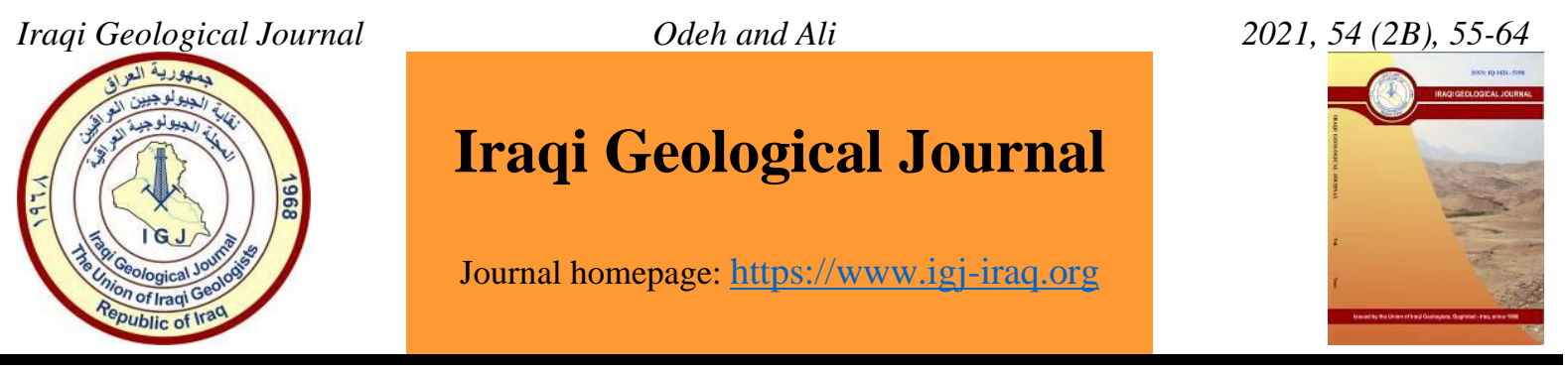

\title{
Structural Interpretation of Yamama and Naokelekan Formations in Tuba Oil Field Using 2D Seismic Data
}

\author{
Belal M. Odeh ${ }^{1, *}$ and Kamal K. Ali ${ }^{2}$ \\ 1 Department of Geology, College of Science, University of Baghdad, Baghdad, Iraq \\ 2 Department of Geology, College of Science, University of Baghdad, Baghdad, Iraq \\ * Correspondence: aljnabyblal86@gmail.com
}

Received: 29 April 2021; Accepted: 5 July 2021; Published: 31 August 2021

\begin{abstract}
This research includes structure interpretation of the Yamama Formation (Lower Cretaceous) and the Naokelekan Formation (Jurassic) using 2D seismic reflection data of the Tuba oil field region, Basrah, southern Iraq. The two reflectors (Yamama and Naokelekan) were defined and picked as peak and tough depending on the 2D seismic reflection interpretation process, based on the synthetic seismogram and well log data. In order to obtain structural settings, these horizons were followed over all the regions. Two-way travel-time maps, depth maps, and velocity maps have been produced for top Yamama and top Naokelekan formations. The study concluded that certain longitudinal enclosures reflect anticlines in the east and west of the study area representing Zubair and Rumaila fold confined between them a fold consist of two domes represents Tuba fold with the same trending of Zubair and Rumaila structures. The study confirmed the importance of this field as a reservoir of the accumulation of hydrocarbons.
\end{abstract}

Keywords: Reflection; Tuba oilfield; Seismic stratigraphy; Jurassic; Cretaceous.

\section{Introduction}

There is through its high analytical capacity and ability to give a close picture to the subsurface geological situation, delineation the type of the oil traps (structural, stratigraphic) with a good estimation of the reservoir characterizations (porosity, lithofacies, fluid content and water saturation) (Telford et al., 1990; Lines and Newrick, 2004; Al-Sadi, 2017; Awadh et al., 2018; Awadh et al., 2019; Awadeesian et al., 2019). The main steps of the seismic reflection method are the acquisition field seismic data, processing then interpretation to get an image, which closes, to the real subsurface geology. Interpretation includes a description of the seismic sections, identify the target reflectors and horizons, their quality, continuity of the reflectors and create two-way time maps, velocity maps, and depth maps to recognize any seismic structures features that may help in interpretation. In the current research, and interpretation of 2D seismic data of one of the important oilfields in Iraq named Tuba oil field. The Tuba oil field was discovered in 1960 as one of the most oil fields in the Mesopotamian basin. the Mishrif Formation, which makes up about $65 \%$ percent of, the extraction rate, is the main reservoir of carbonates in Tuba oil field (Oil Exploration Company, 2013). The main goal of this, article is to interpret the 2D seismic data and the logs of the well of Tuba oil field in order to get an image of the subsurface structure

DOI: $\underline{10.46717 / i g j .54 .2 B .5 M s-2021-08-25}$ 
of the Yamama and Naokelekan Formations of this field. Many seismic studies have been conducted in Iraq over the last decade was aimed to plotting the stratigraphic and structural image of the subsurface geology of different oilfields in Iraq and concluded that the method of seismic reflection provides good evidence of oil accumulation and has helped to understand the geology of the subsurface (Khorshid and Kadhm, 2015).

The study area (Tuba oilfield) is located in Basra, southern Iraq (Fig.1). The Tuba oilfield lies nearly $(35 \mathrm{~km})$ southwest of the city of Basra. The study area is, located between Zubair and Rumaila oil fields area. It lies about $5 \mathrm{~km}$ to the east of Zubair, and about $2 \mathrm{~km}$ to the west of the Rumaila oilfield (Fig.1). It represents an anticline almost has trending N-S, it is $29 \mathrm{~km}$ long, and about $9 \mathrm{~km}$ wide. In 1950, Basra Oil Company performed a gravity survey for most of southern Iraq, including the study area. In 1974, the French Company, CGG conducted a magnetic survey. The results of the interpretations of both surveys have shown that the study area has the same structure direction as the other areas of southern Iraq and may have the same hydrocarbon potential (O.E.C, 2011). In 1960, the first exploratory 2D seismic reflection investigation for the Tuba oil field was carried out in conjunction with other Rumaila and Zubair surveys. Tu-1 well was drilled and reached a depth of 3639.3m (O.E.C, 2011). The study aims to determine the geometric boundaries for the area structures within Yamama and Naokelekan Formations, Using the Direct Hydrocarbon Indicators technique (DHI) to predict the probability of hydrocarbon accumulations.

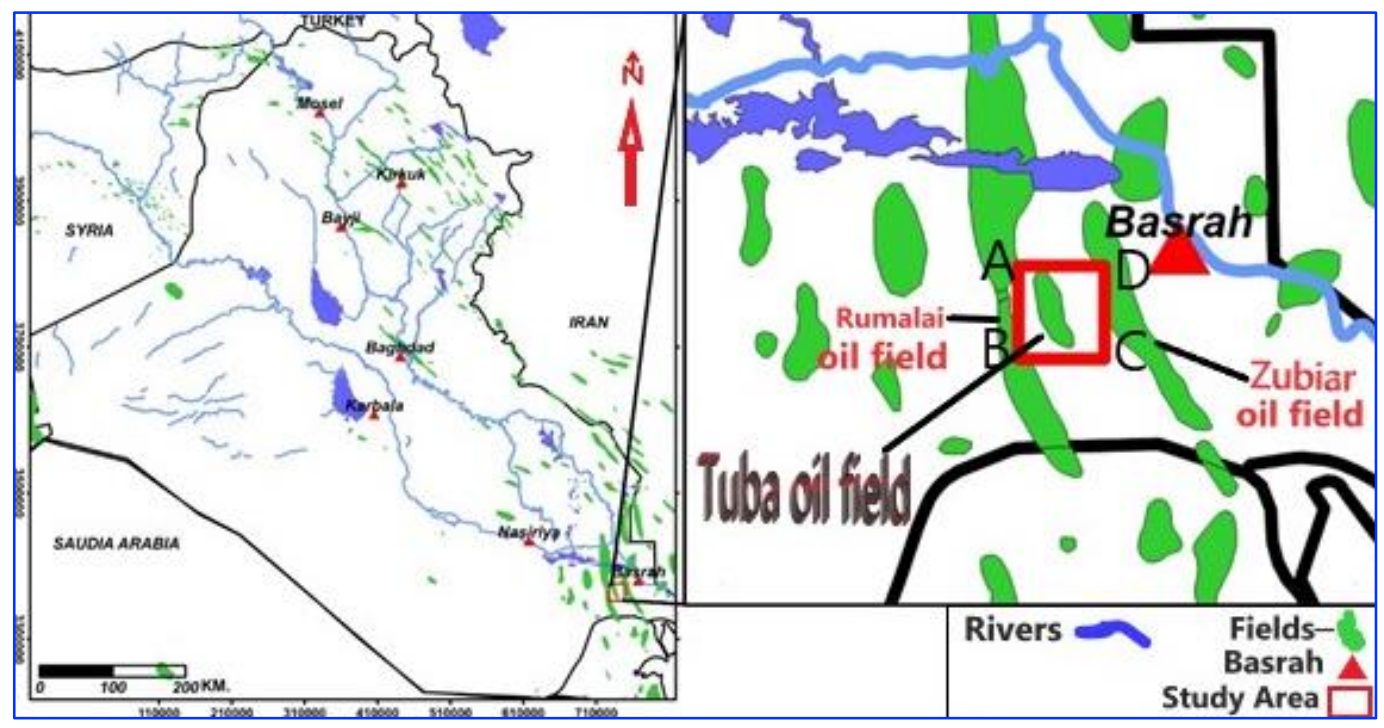

Fig.2. Location map of the study area

\section{Materials and Methods}

2D processed seismic data for 24 lines were obtained from the Iraqi Oil Exploration Company (O.E.C). The Basic map of the study area was built using these seismic data loaded in an interactive, interpretation workstation in SEG-Y format. Two kinds of perpendicular lines are assigned. The base map of the study area is shown in Fig. 2. The 2D seismic data were acquired and processed by O.E.C.in 2011 includes a definition of the geographic coordinates in the UTM coordinates system of the study area. The study deal with 24 lines given names (RR-JS-ZZ) and the area contains five wells, but these wells do not reach the Jurassic era, so a definition was made from the Rumaila, well 172 nearby the study area. 


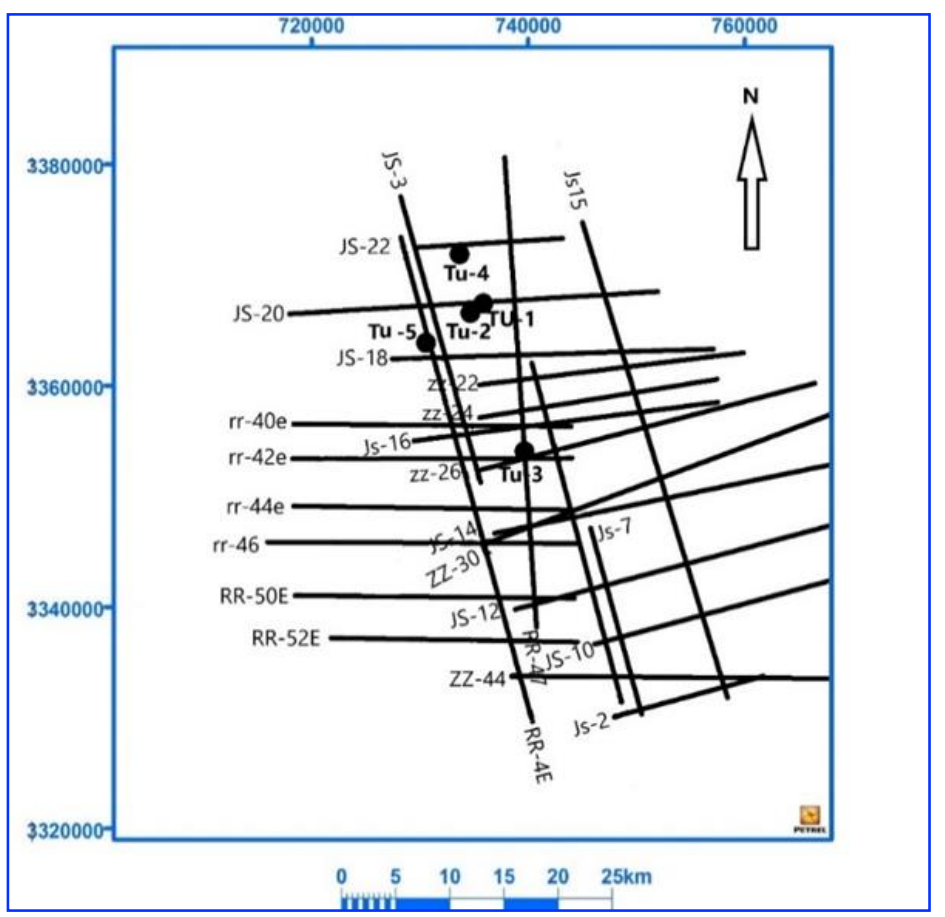

Fig. 2. A base map of the study area shows the seismic lines included in the current study.

\subsection{Generation of Synthetic Seismograms}

A Synthetic Seismogram is the construction of an artificial seismic trace at a well location by application of the convolution concept between the source wavelet and the reflectivity series (that been calculated using acoustic impedance of well data). It is considered an indispensable tool in the interpretation stage to tie the seismic reflection images with the real geological section (seismic-well tie). The main purpose of the synthetic seismogram is to attach the stratigraphic identities for the reflection events diagnosed on the seismic stack section (Lendseth, 1979).

Interpretations of the data can be enhanced by comparing marker beds or other correlation points selected on well logs with significant reflections on the seismic segment. The accuracy of a synthetic seismogram match depends on the quality of well logs, the quality of seismic data processing and the ability to extract a representative wavelet from seismic data (Telford,et al., 1990; Brown, 2011; Al-sadi, 2017). In order to produce acoustic impedance, the acoustic, log is normally calibrated with a checkshot before combining with the density log. The synthetic seismograms for the Tuba- 2 well were prepared, but due to that the drilling wells (Tu-2) did not reach to Jurassic Formations (the target reflector in the current study) in the Tuba oil field, so the definition was made using Rumaila well (Ru172) (Fig. 3). The picked reflector wavelets appeared as peaks and trough on synthetic trace (peak in the top Yamama and trough in the top Naokelekan Formation). The figure illustrates the strong reflection coefficients that predicted for the Yamama and Naokelekan levels.

\section{Results}

The seismic interpretation is an important stage in the seismic exploration job, which includes converting the processed seismic data into the corresponding geological information (Al-sadi, 2017). In general, there are two basic ways to interpret seismic data. The first one is a structural approach, which determines the shape and geometry of reflection horizons from its two-way travel-times and reveals an acceptable image of the structural geology. Secondly, the stratigraphic approach which is the analysis of reflection sequences based on the wavelet amplitude spectrum (frequency and phase) (Sheriff and 
Geldart, 1995). The reflectors were identified and selected based on an analysis of seismic data, synthetic seismograms and well relations. The selected reflectors continuity can be defined as follows. (Fig. 4).

- Yamama reflector has good continuity.

- Naokelekan reflector has moderate continuity.

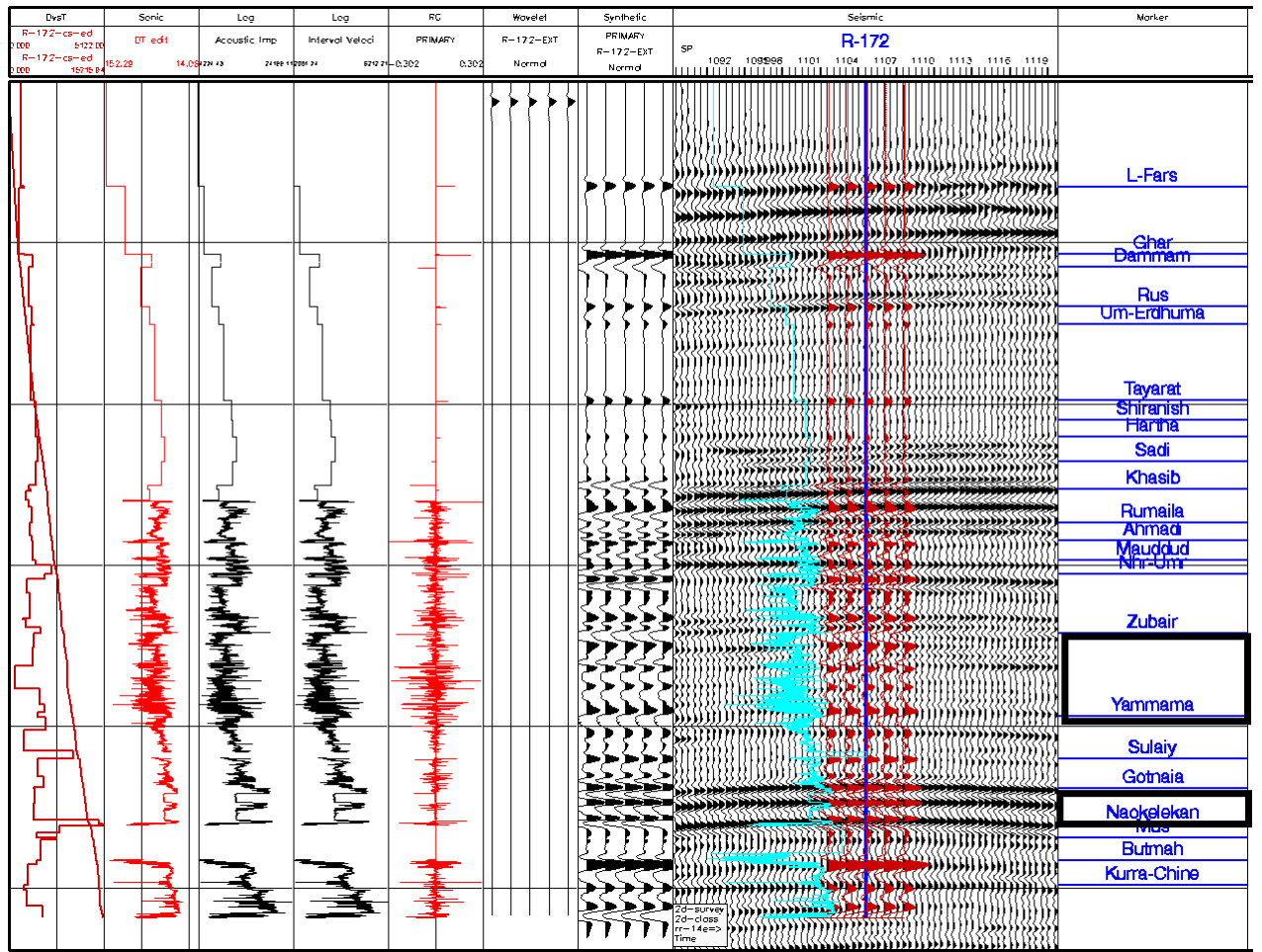

Fig. 3. The synthetic seismogram of the Rumali-172.

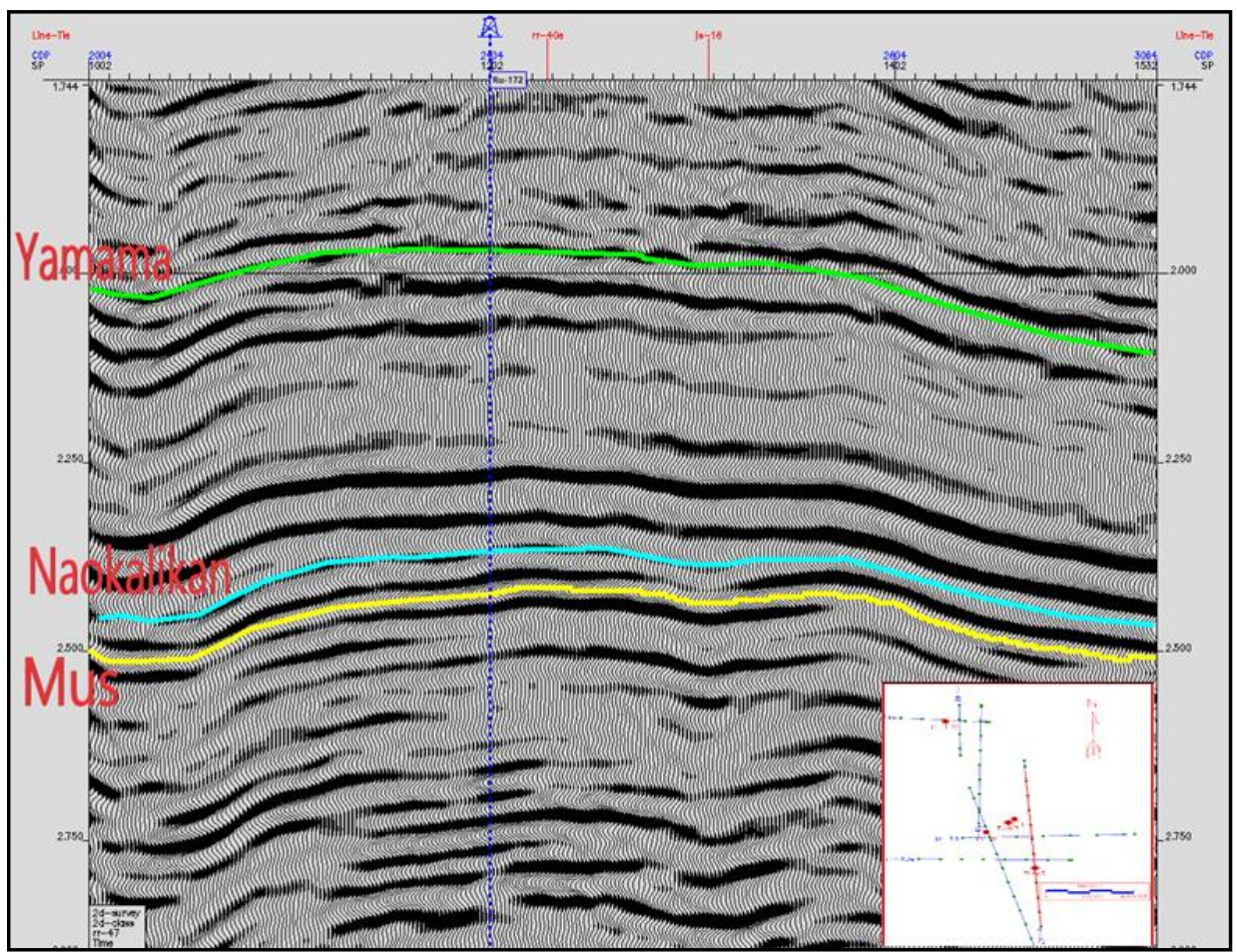

Fig. 4. The Continuity of the picked reflectors (Yamama, Naokelekan) 


\subsection{Structural Images of the Picked Horizons}

To get the structural image of the picked reflectors (Top Yamama Formation and Top Naokelekan) two-way time maps, velocity maps and depth maps were prepared. The following is the description and interpretation of these maps

\subsubsection{Two-way time (TWT) maps}

- Top Yamama TWT map

TWT map of the top Yamama shows the higher value of TWT is towards NW direction and decrease in SW direction of the area. A structural map in the time domain at the reflector plane (1900ms$2200 \mathrm{~ms}$ ) showed that the region is composed of two main parallel longitudinal folds with narrow compositional axes extending in a northwest-southeast direction. The first fold in the east represents the axis of the Al-Zubair fold, while the second represents the axis of the Rumaila fold. These two folds are confined between them a longitudinal fold whose axis is toward northwest-southeast and consists of two domes represents Tuba fold. Three wells were drilled in the northern dome while one well was drilled in a southern dome and another well-drilled outside the fold Anticline and also closure syncline could be seen to the west at Rumaila area. The TWT map shows some structures adjacent to the study area as syncline (given A) and anticline (given B, C, E) (Fig.5).

\section{- Top Naokelekan TWT map}

The TWT map of Top Naokelekan presents a higher value of TWT in NE which means that slope of the reflector towards the NE. The TWT map indicates two main narrow longitudinal parallel folds, the first fold in the east represents the axis of the folding of the Zubair fold and second in the west represents the axis of the folding of Rumaila fold and the two folds are confined between them in which a longitudinal fold extending NW-SE, consisting of one dome(Tuba fold), TWT map shows also, some structures around the study area such as syncline (given A ) is about $2600 \mathrm{~ms}$. While in the W-E of Tuba fold is the anticline (given B-C) is about 2300ms (Fig.6).

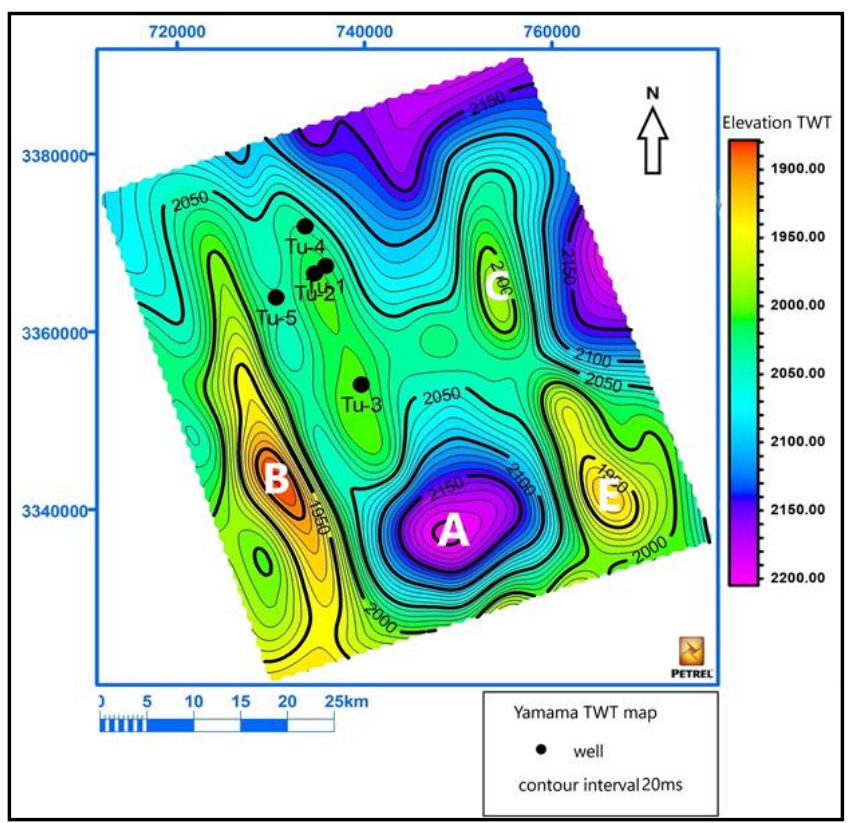

Fig. 5. Two-way time (TWT) map of top Yamama Formation in the study area 


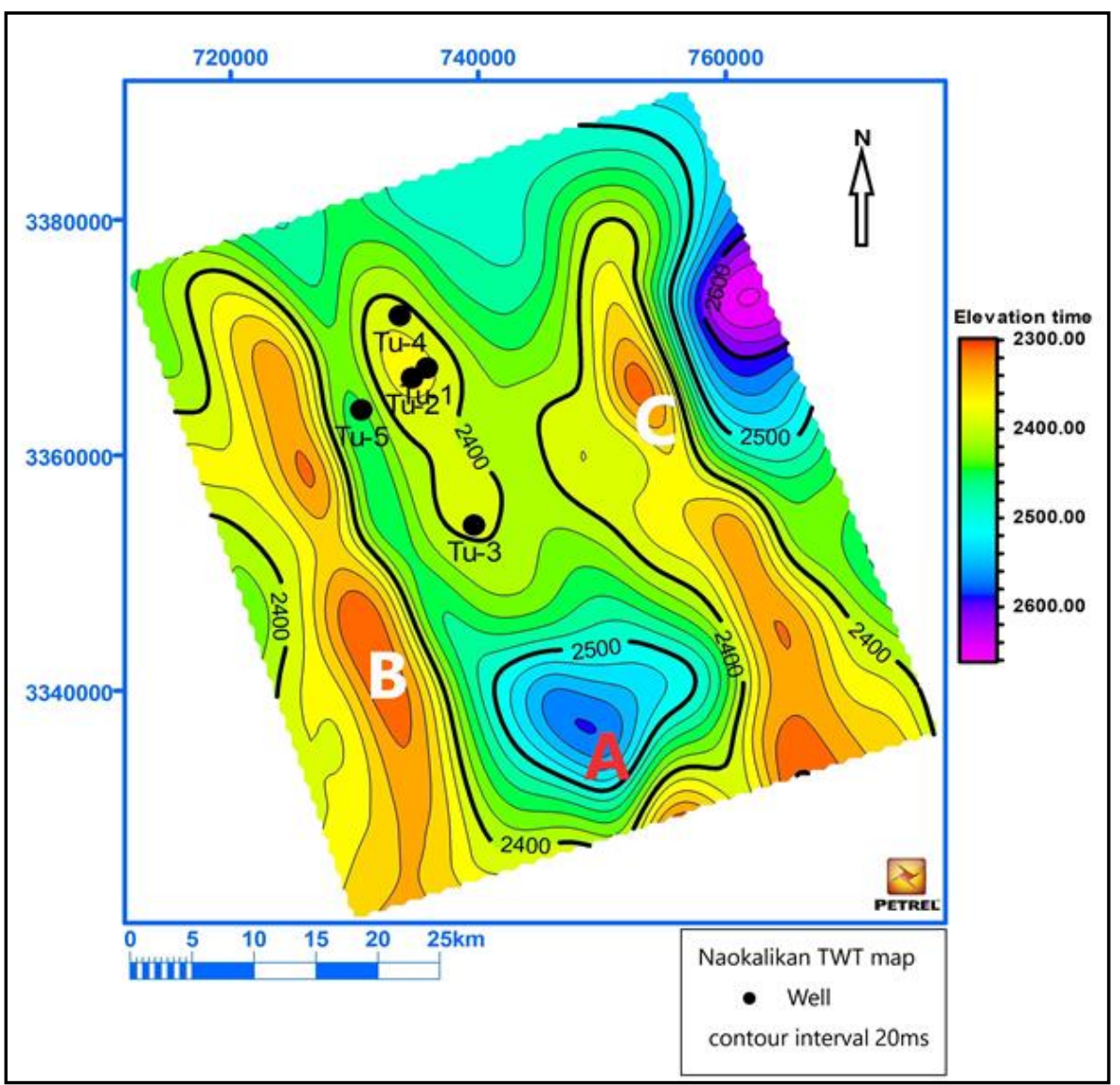

Fig. 6. Two-way time (TWT) map of the top Naokelekan Formation in the study area.

\subsubsection{Velocity maps}

The average velocities in each well were calculated using a Check-shot survey (the velocity can be calculated using the time/depth scale in the check-shot).

- Top Yamama velocity maps

Fig. 7 reveals velocity map of Base Zubair (Top Yamama) (which shows the velocity value increases toward the south direction and decreases toward the north direction, the contour interval is $10 \mathrm{~m} / \mathrm{s}$, velocity range between $(3700-3920)$.

- Top Naokelekan velocity map

Fig. 8 shows the velocity value increases toward the north direction and decreases toward the south direction. The contour interval is $10 \mathrm{~m} / \mathrm{s}$, velocity range between (3840-3880). There is a difference in the direction of velocity between the Yamama and Naokelekan formations due to the difference in the age of the basin. That is because Yamama Formation is of Cretaceous age while Naokelekan Formation is of Jurassic age in addition to the variation in the lithology and physical properties of the rocks in the formations. 


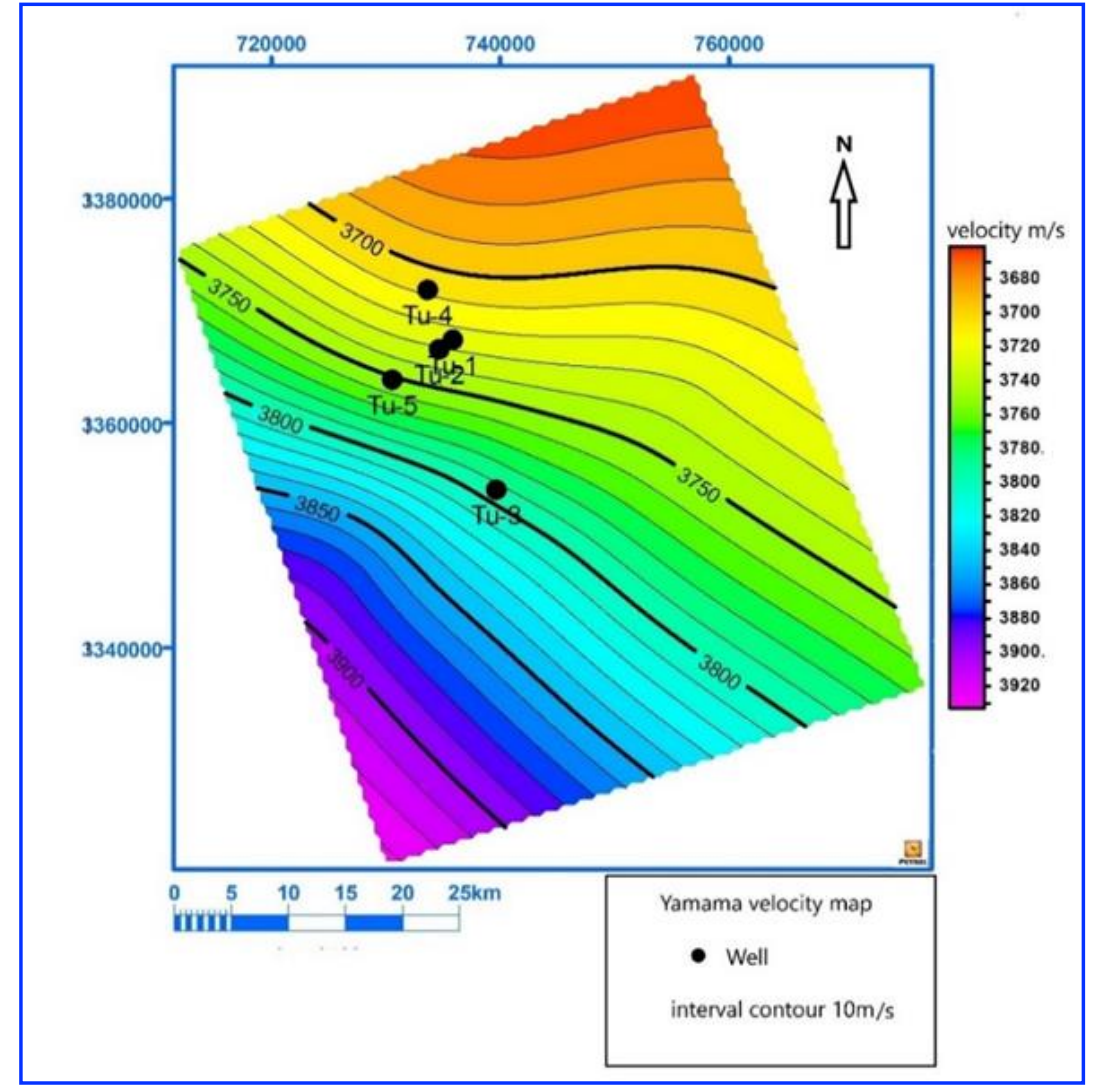

Fig. 7. Velocity map of top Yamama Formation in the study area.

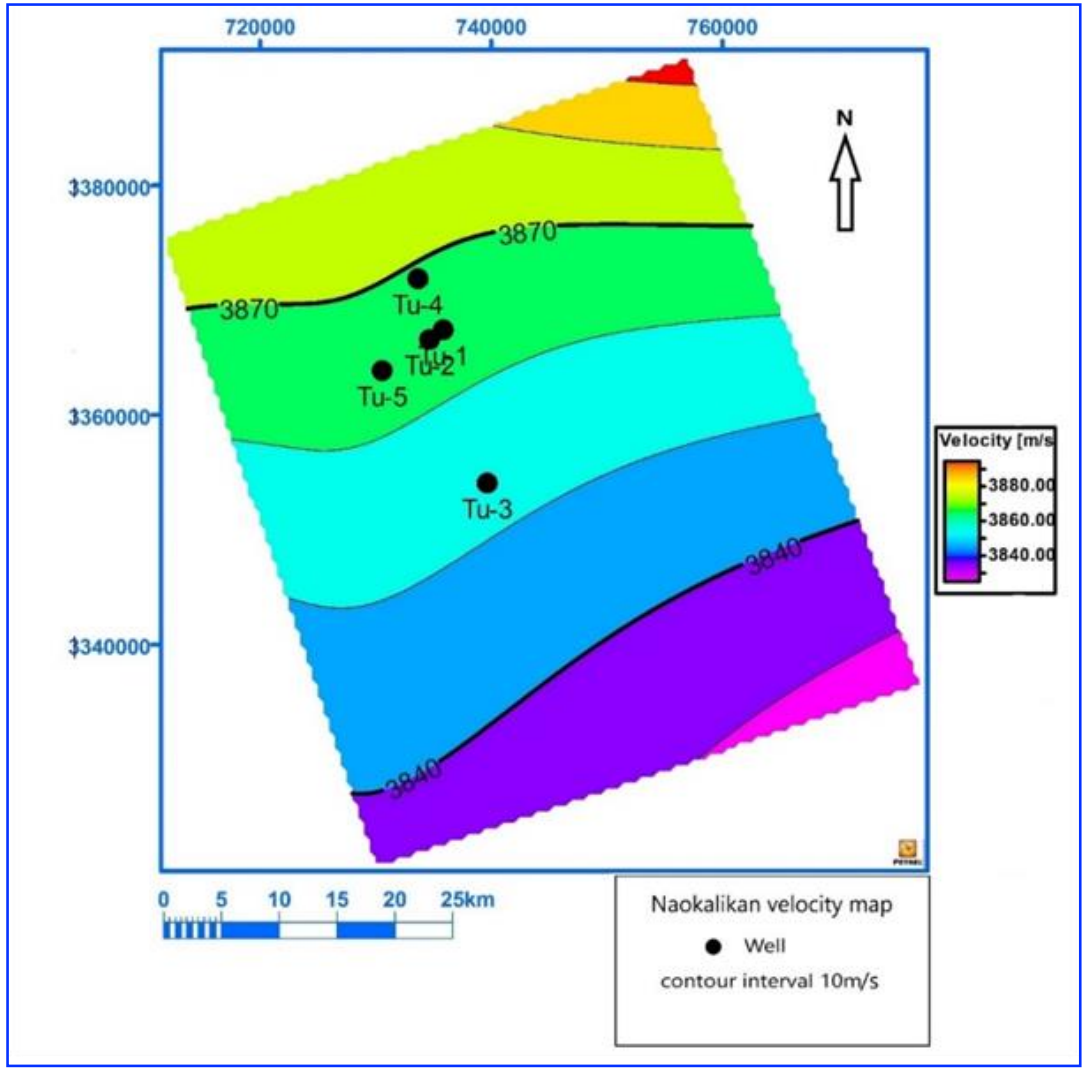

Fig. 8. Velocity map of top Naokelekan Formation in the study area. 


\subsubsection{Depth maps}

- Depth map of Top Yamama

A minimum depth value of 3700-3800 m is noticed at the East and -West parts of the map, these depths which represents anticlines (given B, C, D) of Zubair and Rumaila Folds respectively and gradually increases toward the south reached value of about $4200 \mathrm{~m}$ depth which represents syncline structures (A) and in the eastern border of the map reaches to $4000 \mathrm{~m}$. while the depth is less than $3800 \mathrm{~m}$ at the fold structure which represent Tuba fold in the middle of the study area (Fig. 9).

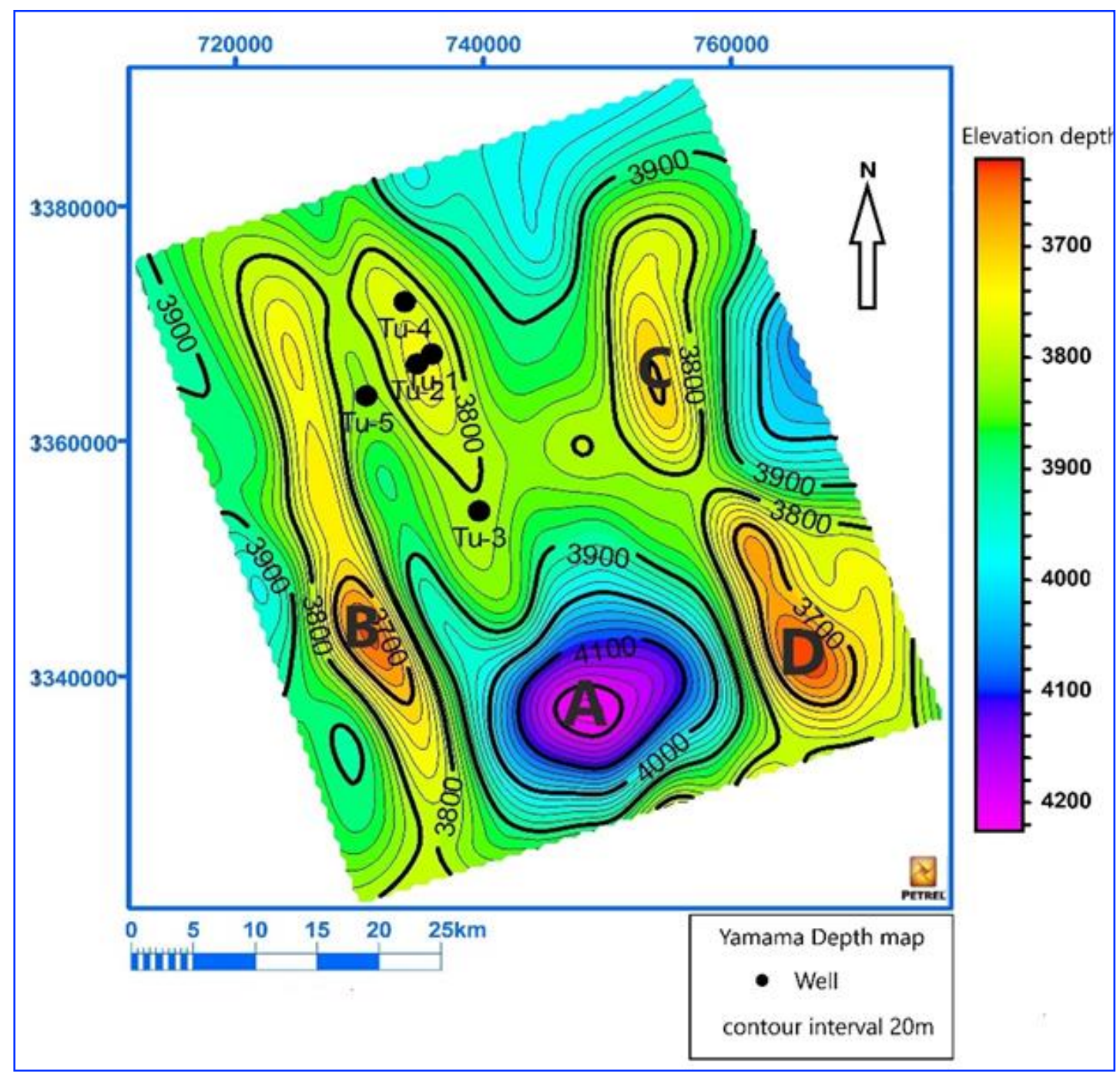

Fig. 9. Depth map of Top Yamama Formation in the study area

\section{- Depth map of Top Naokelekan}

A minimum depth value of (4200) $\mathrm{m}$ which represents anticline (given B, C, D) in East (Zubiar fold and in the-West (Rumaila fold) of the study area. These two folds are confined between them in which a longitudinal fold extending NW-SE represents Tuba fold with depth about $4300 \mathrm{~m}$. The depth gradually increases toward the south and east of the study area reached (4600-4700) $\mathrm{m}$ which represents syncline (given A). (Fig. 10). 


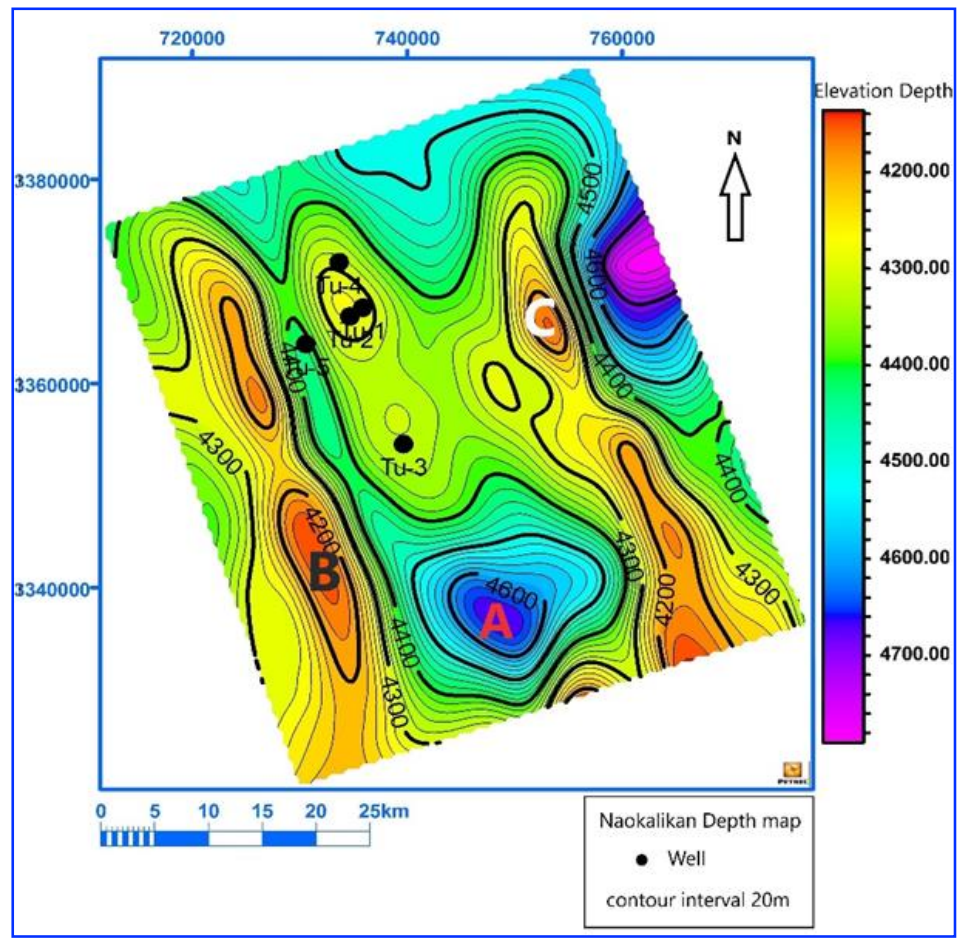

Fig. 10. Depth map of Top Naokelekan Formation in the study area

\section{Discussions}

By reviewing the previous studies, we were able to confirm the following observations: 1- The lack of clarity of the structural image of the field, as it consists of one or two domes. 2- The structural relationship between it and the adjacent fields is not clear. The structure image summarized by our current study differs from the previous image and it is clear that the field consists of the main dome with an N-S direction that deviates slightly towards the west on the northwestern side towards the boundary between the northern and southern right of Rumaila and this dome is drilled in the wells of $(1,2,3,4$, 5). The dimensions of this dome are $13 \mathrm{~km}$ in length, $6.5 \mathrm{~km}$ in width, $25 \mathrm{~m}$ thickness in top Yamama Formation.

\section{Conclusions}

Two reflectors Yamama and Naokelekan formations are defined using synthetic seismogram in the time domain for well Tuba-2 and Ru-172.Wavelet appeared as peak /trough due to the difference in reflection coefficient. The interpretation of TWT, average velocity and depth maps give a good image of the structure of the Yamama and Naokelekan horizon. The TWT maps present a higher value of TWT in the south of the study area which means that the reflector slopping towards the south of the area. Also, the TWT maps show clearly the two known Zubair and Rumaila folds trending NW-SE direction confined between them the Tuba fold trending in the same direction. In addition to some other structures adjacent to the study area were recognized, as closure structures (anticline and syncline), the average velocity maps to the target reflectors show that the velocity increase toward the $\mathrm{S}$ direction. There is a difference in the direction of velocity between the Yamama and Naokelekan formations due to the difference in the age of the basin, the difference in lithology this information is not mentioned in the text of the manuscript. The studied reflectors have velocities range between (3700-3920) $\mathrm{m} / \mathrm{s}$ to Yamama reflectors and (3840-3880) $\mathrm{m} / \mathrm{s}$ to Naokelekan reflector. The depth maps of the studied horizon give a more accurate structure picture than that of TWT map so these maps show the structural configuration 
of Tuba oil field area as a fold consists of two domes with trending NW-SE direction. Depth maps illustrate that depth increase gradually from the south and decrease towed west and west of Tuba oil field. The Tuba structure represents an important reservoir of the Jurassic period and is considered as an important exploration target after the Cretaceous period reservoirs in southern Iraq.

\section{Acknowledgements}

The authors are very grateful to the Editor in Chief Prof. Dr. Salih M. Awadh, the Secretary of Journal Mr. Samir R. Hijab. and the Technical Editors for their great efforts and valuable comments.

\section{References}

Al-Sadi, H. N., 2017, Seismic hydrocarbon exploration: 2D and 3D Techniques, springer international publishing, Switzerland, 331pp.

Awadeesian, A.M., Awadh, S.M., Al-Dabbas, M.A., Al-Maliki, M.M., Al-Jawad, S.N. and Hussein, A.K.S., 2019. A modified water injection technique to improve oil recovery: Mishrif carbonate reservoirs in Southern Iraq oil fields, case study. The Iraqi Geological Journal, pp.125-146.

Awadh, S.M., Al-Auweidy, M.R. and Al-Yaseri, A.A., 2019. Hydrochemistry as a tool for interpreting brine origin and chemical equilibrium in oilfields: Zubair reservoir southern Iraq case study. Applied Water Science, 9(3), pp.1-12.

Awadh, S.M., Al-Mimar, H.S. and Al-Yaseri, A.A., 2018. Salinity mapping model and brine chemistry of Mishrif reservoir in Basrah oilfields, Southern Iraq. Arabian Journal of Geosciences, 11(18), 1-12.

Brown, R. 2011. Prejudice: Its social psychology. John Wiley \& SonsPP350.

Khorshid S. Z., and Kadhm A.D., 2015. Subsurface investigation of Oligocene geological formation age, East Baghdad oilfield. Iraqi Journal of Science, 57(1), 154-162.

Lindseth, R. O. 1979. Synthetic sonic logs, A process for stratigraphic interpretation. Geophysics, 44(1), 3-26.

Lines, L. R., \& Newrick, R. T. 2004. Fundamentals of geophysical interpretation. Society of Exploration Geophysicists 559 pp.

Oil Exploration Company - board processing and interpretations. 2011. Study re-interpretations of seismic information on the Tuba field, $55 \mathrm{pp}$.

Oil Exploration Company, 2013. Reinterpretation seismic data of Tuba oil field70 pp.

Sheriff, R. E., \& Geldart, L. P.,1995. Exploration seismology. Cambridge university press.

Telford, W. M., Geldart, L. P., Sheriff, R. E., \& Sheriff, R. E. 1990. Applied geophysics. Cambridge university number of press. 